NASA/TM-2003-212290

\title{
On the Physics of Flow Separation Along a Low Pressure Turbine Blade Under Unsteady Flow Conditions
}

Meinhard T. Schobeiri and Burak Öztürk

Texas A\&M University, College Station, Texas

David E. Ashpis

Glenn Research Center, Cleveland, Ohio 
Since its founding, NASA has been dedicated to the advancement of aeronautics and space science. The NASA Scientific and Technical Information (STI) Program Office plays a key part in helping NASA maintain this important role.

The NASA STI Program Office is operated by Langley Research Center, the Lead Center for NASA's scientific and technical information. The NASA STI Program Office provides access to the NASA STI Database, the largest collection of aeronautical and space science STI in the world. The Program Office is also NASA's institutional mechanism for disseminating the results of its research and development activities. These results are published by NASA in the NASA STI Report Series, which includes the following report types:

- $\quad$ TECHNICAL PUBLICATION. Reports of completed research or a major significant phase of research that present the results of NASA programs and include extensive data or theoretical analysis. Includes compilations of significant scientific and technical data and information deemed to be of continuing reference value. NASA's counterpart of peerreviewed formal professional papers but has less stringent limitations on manuscript length and extent of graphic presentations.

- TECHNICAL MEMORANDUM. Scientific and technical findings that are preliminary or of specialized interest, e.g., quick release reports, working papers, and bibliographies that contain minimal annotation. Does not contain extensive analysis.

- CONTRACTOR REPORT. Scientific and technical findings by NASA-sponsored contractors and grantees.
- CONFERENCE PUBLICATION. Collected papers from scientific and technical conferences, symposia, seminars, or other meetings sponsored or cosponsored by NASA.

- SPECIAL PUBLICATION. Scientific, technical, or historical information from NASA programs, projects, and missions, often concerned with subjects having substantial public interest.

- TECHNICAL TRANSLATION. Englishlanguage translations of foreign scientific and technical material pertinent to NASA's mission.

Specialized services that complement the STI Program Office's diverse offerings include creating custom thesauri, building customized databases, organizing and publishing research results ... even providing videos.

For more information about the NASA STI Program Office, see the following:

- Access the NASA STI Program Home Page at http://www.sti.nasa.gov

- E-mail your question via the Internet to help@sti.nasa.gov

- Fax your question to the NASA Access Help Desk at 301-621-0134

- Telephone the NASA Access Help Desk at 301-621-0390

- Write to:

NASA Access Help Desk

NASA Center for AeroSpace Information 7121 Standard Drive

Hanover, MD 21076 
NASA/TM-2003-212290

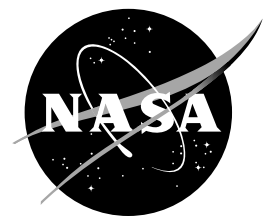

\section{On the Physics of Flow Separation Along a Low Pressure Turbine Blade Under Unsteady Flow Conditions}

Meinhard T. Schobeiri and Burak Öztürk

Texas A\&M University, College Station, Texas

David E. Ashpis

Glenn Research Center, Cleveland, Ohio

Prepared for the

Turbo Expo 2003

cosponsored by the American Society of Mechanical Engineers and the International Gas Turbine Institute

Atlanta, Georgia, June 16-19, 2003

National Aeronautics and

Space Administration

Glenn Research Center 


\section{Acknowledgments}

The presented study is a part of the NASA Glenn Research Center Low Pressure Turbine Flow Physics Program. Meinhard T. Schobeiri and Burak Öztürk acknowledge the support by NASA Cooperative Agreement NCC3-793. The authors also gratefully acknowledge Pratt \& Whitney for providing the blade coordinates.

This report contains preliminary findings, subject to revision as analysis proceeds.

Trade names or manufacturers' names are used in this report for identification only. This usage does not constitute an official endorsement, either expressed or implied, by the National Aeronautics and Space Administration.

The Propulsion and Power Program at NASA Glenn Research Center sponsored this work.

Available from

NASA Center for Aerospace Information 7121 Standard Drive

Hanover, MD 21076
National Technical Information Service 5285 Port Royal Road Springfield, VA 22100 
Proceeding of the ASME Turbo Expo 2003

Power for Land, Sea, and Air

June 16-19, 2003, Atlanta, Georgia, USA

GT-2003-38917

\section{ON THE PHYSICS OF FLOW SEPARATION ALONG A LOW PRESSURE TURBINE BLADE UNDER UNSTEADY FLOW CONDITIONS}

\author{
Meinhard T. Schobeiri and Burak Öztürk \\ Texas A\&M University \\ Turbomachinery Performance and Flow Research Laboratory \\ College Station, Texas 77843
}

\author{
David E. Ashpis \\ National Aeronautics and Space Administration \\ Glenn Research Center \\ Cleveland, Ohio 44135-3191
}

\begin{abstract}
The present study, which is the first of a series of investigations dealing with specific issues of low pressure turbine (LPT) boundary layer aerodynamics, is aimed at providing detailed unsteady boundary flow information to understand the underlying physics of the inception, onset, and extent of the separation zone. A detailed experimental study on the behavior of the separation zone on the suction surface of a highly loaded LPT-blade under periodic unsteady wake flow is presented.
\end{abstract}

Experimental investigations were performed at Texas A\&M Turbomachinery Performance and Flow Research Laboratory using a large-scale unsteady turbine cascade research facility with an integrated wake generator and test section unit. To account for a high flow deflection of LPT-cascades at design and offdesign operating points, the entire wake generator and test section unit including the traversing system is designed to allow a precise angle adjustment of the cascade relative to the incoming flow. This is done by a hydraulic platform, which simultaneously lifts and rotates the wake generator and test section unit. The unit is then attached to the tunnel exit nozzle with an angular accuracy of better than $0.05^{\circ}$, which is measured electronically.
Utilizing a Reynolds number of 110,000 based on the blade suction surface length and the exit velocity, one steady and two different unsteady inlet flow conditions with the corresponding passing frequencies, wake velocities and turbulence intensities are investigated using hot-wire anemometry. In addition to the unsteady boundary layer measurements, blade surface pressure measurements were performed at $\mathrm{Re}=$ $50,000,75,000,100,000$, and 125,000 at one steady and two periodic unsteady inlet flow conditions.

Detailed unsteady boundary layer measurement identifies the onset and extent of the separation zone as well as its behavior under unsteady wake flow. The results presented in ensemble-averaged and contour plot forms contribute to understanding the physics of the separation phenomenon under periodic unsteady wake flow. Several physical mechanisms are discussed.

\section{NOMENCLATURE}

c blade chord

$\begin{array}{ll}\mathrm{c}_{\mathrm{ax}} & \text { axial chord } \\ \mathrm{C}_{\mathrm{p}} & \text { pressure coefficient, } C_{p}=\frac{p-p_{1}}{\left(p_{t}-p\right)_{\text {inl }}} \\ \mathrm{d}_{\mathrm{R}} & \text { rod diameter }\end{array}$

$\mathrm{d}_{\mathrm{R}} \quad$ rod diameter

$\mathrm{M}$ number of samples

$\mathrm{N}$ number of wake cycles

$\mathrm{p}, \mathrm{p}_{\mathrm{t}} \quad$ static, total pressure

$\mathrm{p}_{1} \quad$ static pressure of first tap on suction surface

$\operatorname{Re} \quad$ Reynolds number $\operatorname{Re}=S_{0} V_{\text {exit }} / v$ 


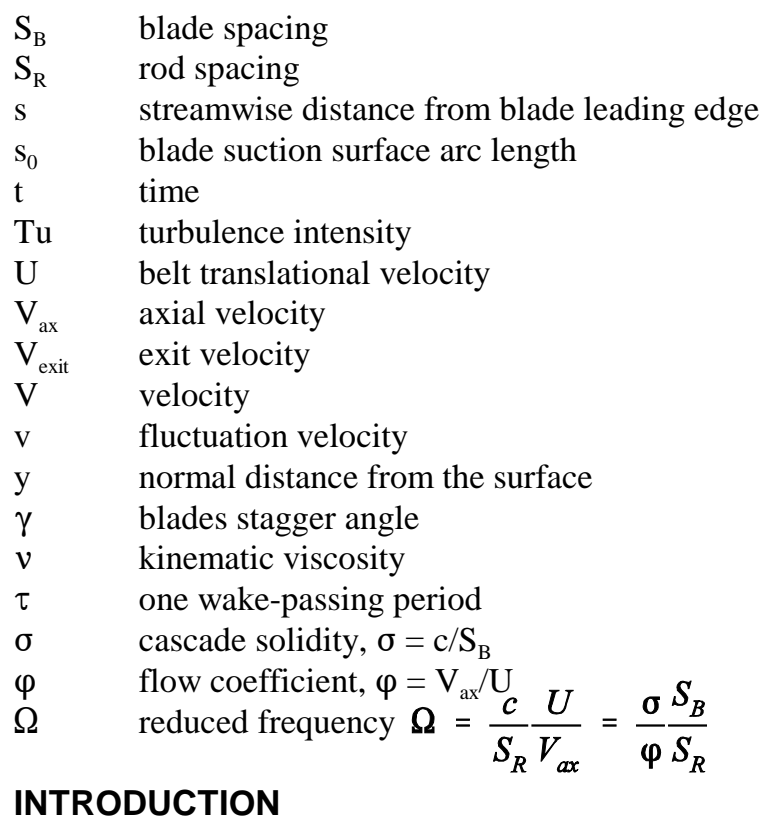

In recent years gas turbine engine aerodynamicists have focused their attention on improving the efficiency and performance of the low pressure turbine (LPT) component. Research at industry, research centers, and academia has shown that reduction in blade count can be achieved without substantially sacrificing the efficiency of the LPT-blading. This reduction contributes to an increase in thrust/weight ratio, thus reducing the fuel consumption. Contrary to the high pressure turbine (HPT) that operates in a relatively high Reynolds number environment, the LPT experiences a variation in Reynolds number ranging from 50,000 to 250,000 dependent on operation conditions. Since the major portion of the boundary layer, particularly along the suction surface, is laminar, the low Reynolds number in conjunction with the local adverse pressure gradient makes it susceptible to flow separation, thus increasing the complexity of the LPT- boundary layer aerodynamics. The periodic unsteady nature of the incoming flow associated with wakes substantially influences the boundary layer development including the onset and extent of the laminar separation and its turbulent re-attachment. Of particular relevance in context of LPT-aerodynamics is the interaction of the wake flow with the suction surface separation zone. While the phenomenon of the unsteady boundary layer development and transition in the absence of separation zones has been the subject of intensive research that has led to better understanding the transition phenomenon, comprehending the multiple effect of mutually interacting parameters on the LPT-boundary layer separation and their physics still requires more research.
The significance of the unsteady flow effect on the efficiency and performance of compressor and turbine stages was recognized in the early seventies by several researchers. Fundamental studies by Pfeil and Herbst [1], Pfeil et al. [2], and Orth [3] studied and quantified the effect of unsteady wake flow on the boundary layer transition along flat plates. Schobeiri and his coworkers $[4,5,6,7]$ experimentally investigated the effects of periodic unsteady wake flow and pressure gradient on the boundary layer transition and heat transfer along the concave surface of a constant curvature plate. The measurements were systematically performed under different pressure gradients and unsteady wake frequencies using a squirrel cage type wake generator positioned upstream of the curved plate. Liu and Rodi [8] carried out boundary layer and heat transfer measurements on a turbine cascade, which was installed downstream of a squirrel cage type wake generator mentioned previously.

Analyzing the velocity and the turbulence structure of the impinging wakes and their interaction with the boundary layer, Chakka and Schobeiri [7] developed an intermittency based unsteady boundary layer transition model. The analysis revealed a universal pattern for the relative intermittency function for all frequencies and pressure gradient investigated. However, the above investigations were not sufficient to draw any conclusion with regard to universal character of the relative intermittency function. Further detailed investigations of the unsteady boundary layer along a high Reynolds number turbine blade of the Space Shuttle Main Engine (SSME) by Schobeiri et al. [9] and its subsequent analysis [10], [11], and [12] verified the universal character of the relative intermittency function. For this purpose, Schobeiri et al. [9] utilized a conceptually different type wake generator, which is also used for the investigation presented in this paper. Fottner and his co-workers [13], [14] and Schulte and Hodson [15] used the same wake generating concept for investigating the influence of unsteady wake flow on the LPT-boundary layer. Kaszeta, Simon, and Ashpis [16] experimentally investigated the effect of unsteady wakes on laminar-turbulent transition within a channel with the side walls simulating the suction and pressure surfaces of a LPT-blade. They utilized a retractable cascade of cylindrical rods for generating the unsteady wakes. Lou and Hourmouziadis [17] experimentally investigated the effect of oscillating inlet flow conditions on laminar boundary layer separation along a flat plate under a strong negative pressure gradient which was imposed by the opposite wall. 
Using the surface mounted hot film measurement technique, Fottner and his co-workers [13], [14] Schröder [18], and Haueisen, Schröder, and Hennecke [19] documented strong interaction between wakes and the suction surface separation zone on LPT- blades, both in wind tunnel cascade tests and in turbine rig. Furthermore, they investigated the boundary layer transition under the influence of periodic wakes along the LPT-surface and found that the interaction of wakes with the boundary layer greatly affects the loss generation. Investigations by Halstead et al. [20] on a large-scale LP-turbine use surface mounted hot films to acquire detailed information about the quasi-shear stress directly on the blade surface. As investigations by Cardamone et al. [14] and Schröder [18] indicate, the benefit of the wake-boundary layer interaction can be used for design procedure of modern gas turbine engines with reduced LPT- blade number without altering the stage efficiency.

Most of the above mentioned studies on LP-turbine cascade aerodynamics have largely concentrated on the measurement of the signals stemming from hot film mounted on the suction and pressure surfaces of the blades under investigation. Although this technique is effective in qualitatively reflecting the interaction of the unsteady wake with the boundary layer, because of lack of an appropriate calibration method, it is not capable of quantifying the surface properties such as the wall shear stress. The few boundary layer measurements are not comprehensive enough to provide any conclusive evidence for interpretation of the boundary layer transition and separation processes and their direct impact on the profile loss, which is a critical parameter for blade design. Furthermore, numerical simulation of unsteady LPT-blade aerodynamics using conventional turbulence and transition models fails if applied to low Reynolds number cases. Recent work presented by Cardamone et al. [14] shows that in the steady state case at $\mathrm{Re}=60,000$, the separation is captured, however, in the unsteady case, the separation zone is not reproduced.

The objective of the present study, which is the first of a series of investigations dealing with specific issues of LPT-boundary layer aerodynamics, is to provide detailed unsteady boundary flow information to understand the underlying physics of the inception, onset, and extent of the separation zone. Furthermore, the unsteady boundary layer data from the present and planned experimental investigations will serve to extend the intermittency based unsteady boundary layer transition model developed by Schobeiri and his co- workers $[7,11,12]$ to the LPT-cases, where separation occurs on the suction surface at low Reynolds number at design and off-design points. Furthermore, the experimental results are intended to serve as a benchmark data for comparison with numerical computation using DNS, LES or RANS-codes.

It is well known that boundary layer measurement is one of the time consuming aerodynamic measurements. Any attempt to increase the number of parameters to be studied would inevitably result in substantial increase of the measurement time. Considering this fact, the research facility described in [9] and [10] with state-of-the-art instrumentation has been substantially modified to study systematically and efficiently the influence of periodic unsteady and highly turbulent flow on LPT-cascade aerodynamics at the design and off-design incidence angles, where Reynolds number, wake impingement frequency, free-stream turbulence, and the blade solidity can be varied independently.

\section{EXPERIMENTAL RESEARCH FACILITY}

To investigate the effect of unsteady wake flow on turbine and compressor cascade aerodynamics, particularly on unsteady boundary layer transition, a multi-purpose large-scale cascade research facility was designed and has been taken into operation since 1993. Since the facility in its original configuration is described in [9] and [10], only a brief description of the modifications and the main components is given below. The research facility consists of a large centrifugal air supplier, a diffuser, a settling chamber, a nozzle, an unsteady wake generator, and a turbine cascade test section (Fig. 1). An air supplier with a volumetric flow rate of $15 \mathrm{~m}^{3} / \mathrm{s}$ is capable of generating a maximum mean velocity of $100 \mathrm{~m} / \mathrm{s}$ at the test section inlet. The settling chamber consists of five screens and one honeycomb flow straightener to control the uniformity of the flow.

Two-dimensional periodic unsteady inlet flow is simulated by the translational motion of a wake generator (see Fig. 1), with a series of cylindrical rods attached to two parallel operating timing belts driven by an electric motor. To simulate the wake width and spacing originating from the trailing edge of rotor blades, the diameter and number of rods can be varied. The rod diameter, its distance from the LPT-blade leading edge, the wake width and the corresponding drag coefficient are chosen according to the criteria outlined by Schobeiri et al. [21]. 


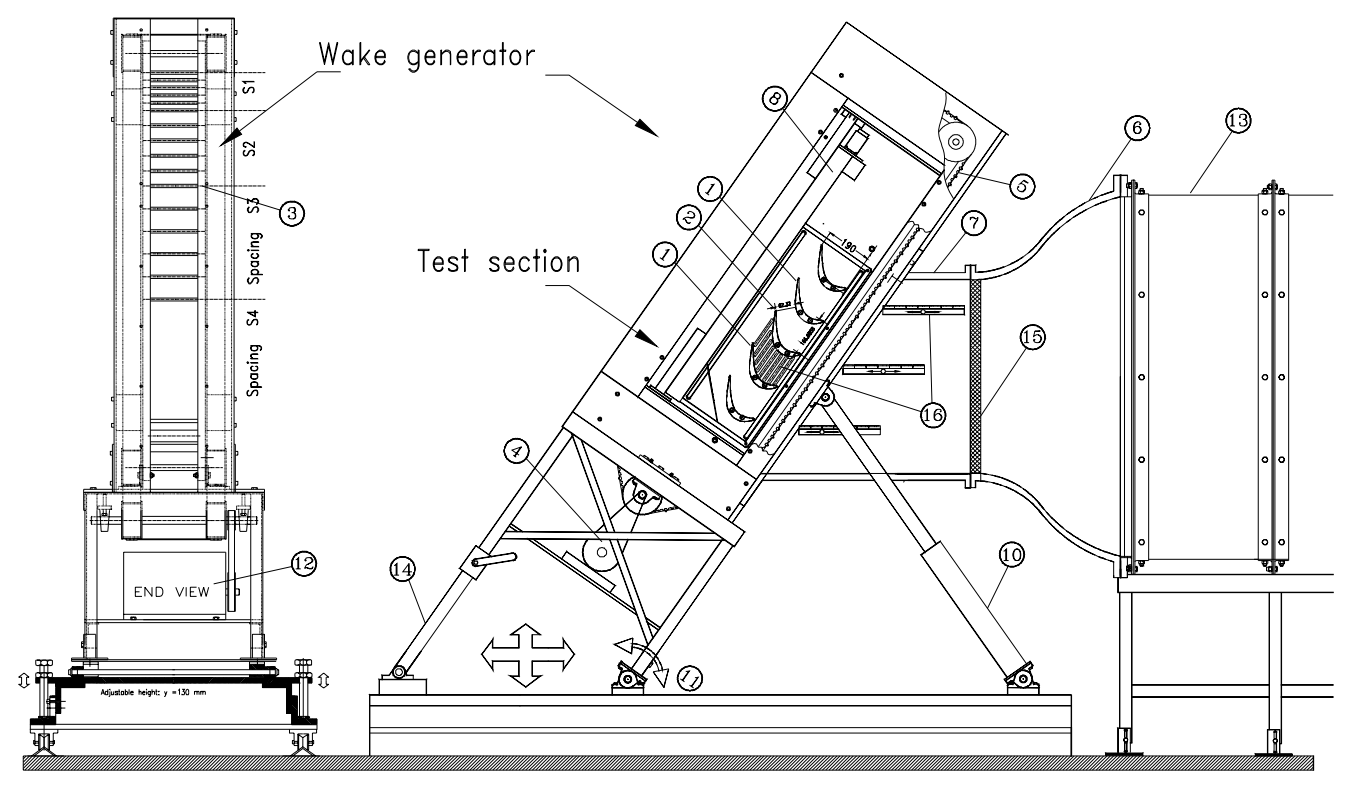
(1) Static pressure blade
(5) Timing belts. rod attachments
(9) Inlet nozzle
(10) Hydraulic cylinders
(13) Large silence chamber with
(2) Blade with hot film sensors
(6) Transition duct
(11) Pivot point
Telescope supprt
(3) Wake generating rods
(7) Straight duct
(12) Wake generator e-motor
(15) Honeycomb flow straightener
(4) Wake generator
(8) Traversing system
(16) Traversing slots

Fig. 1: Turbine cascade research facility with the components and the adjustable test section.
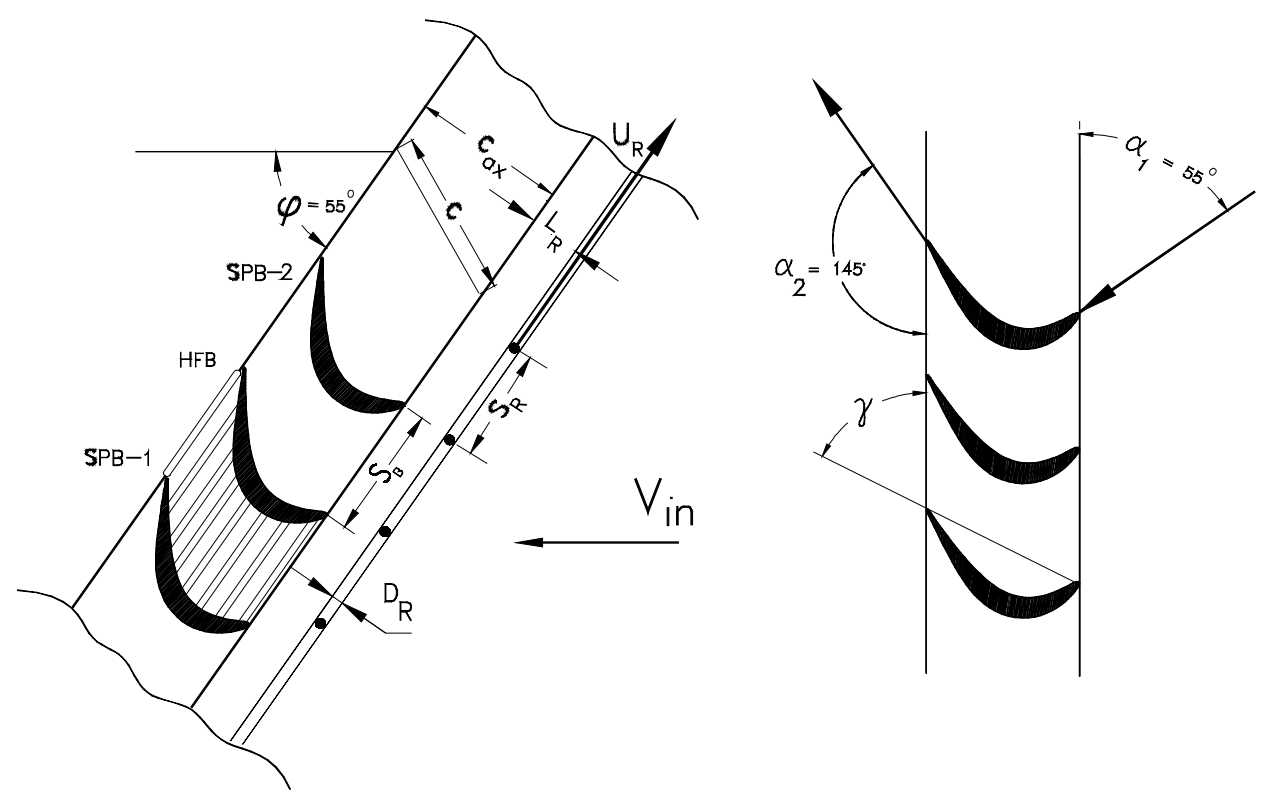

Fig. 2: Cascade geometry and stagger angle are listed in Table 1. Number of blades $=5$, SPB-1 and SPB-2 are blades with static pressure taps, HFB is instrumented with surface mounted hot films to be used for future investigations. 
Table 1: Parameters of turbine cascade test section .

\begin{tabular}{|l|l|l|l||}
\hline \multicolumn{1}{|c|}{ Parameters } & \multicolumn{1}{|c|}{ Values } & \multicolumn{1}{c|}{ Parameters } & \multicolumn{1}{c||}{ Values } \\
\hline \hline Inlet velocity & $\mathrm{V}_{\mathrm{in}}=4 \mathrm{~m} / \mathrm{s}$ & Inlet turbulence intensity & $\mathrm{Tu}_{\mathrm{in}}=1.0 \%$ \\
\hline Rod translational speed & $\mathrm{U}=5.0 \mathrm{~m} / \mathrm{s}$ & Blade Re-number & $\mathrm{Re}=110,000$ \\
\hline Nozzle width & $\mathrm{W}=200.0 \mathrm{~mm}$ & Blade height & $\mathrm{h}_{\mathrm{B}}=200 \mathrm{~mm}$ \\
\hline Blade chord & $\mathrm{c}=203.44 \mathrm{~mm}$ & Blade stagger angle & $\gamma=26^{\circ}$ \\
\hline Blade axial chord & $\mathrm{c}_{\mathrm{ax}}=182.85 \mathrm{~mm}$ & Cascade solidity & $\sigma=1.248$ \\
\hline Blade suction surface length & $\mathrm{L}_{\mathrm{SS}}=270.32 \mathrm{~mm}$ & Cascade angle & $\delta=55^{\circ}$ \\
\hline Cascade flow coefficient & $\Phi=0.80$ & Cascade spacing & $\mathrm{S}_{\mathrm{B}}=163 \mathrm{~mm}$ \\
\hline Inlet air angle, Fig. 2 & $\alpha_{1}=35.0^{\circ}$ & Exit air angle, Fig. 2 & $\alpha_{2}=145.0^{\circ}$ \\
\hline Rod diameter & $\mathrm{D}_{\mathrm{R}}=2.0 \mathrm{~mm}$ & Rod distance to lead. edge & $\mathrm{L}_{\mathrm{R}}=122 \mathrm{~mm}$ \\
\hline Cluster 1 (no rod, steady) & $S_{R}=\infty$ & $\Omega$ - parameter steady case & $\Omega=0.0$ \\
\hline Cluster 2 rod spacing & $S_{R}=160.0 \mathrm{~mm}$ & $\Omega$ - parameter for cluster 1 & $\Omega=1.59$ \\
\hline Cluster 3 rod spacing & $S_{R}=80.0 \mathrm{~mm}$ & $\Omega$ - parameter for cluster 2 & $\Omega=3.18$ \\
\hline \hline
\end{tabular}

The belt-pulley system is driven by an electric motor and a frequency controller. The wake-passing frequency is monitored by a fiber-optic sensor. The sensor also serves as the triggering mechanism for data transfer and its initialization, which is required for ensembleaveraging. This type of wake generator produces clean two-dimensional wakes, whose turbulence structure, decay and development is to a great extent predictable [21]. The facility was used for many unsteady boundary layer transition and heat transfer investigations [9-12] that serve as benchmark data for validation of turbulence and transition models and for general code assessments.

To account for the inlet flow angle and a high flow deflection of LPT-cascade, the entire wake generator and test section unit including the traversing system were modified to allow a precise angle adjustment of the cascade relative to the incoming flow. This is done by a hydraulic platform, which simultaneously lifts and rotates the wake generator and test section unit. The unit is then attached to the tunnel exit nozzle with an angular accuracy less than $0.05^{\circ}$, which is measured electronically.
The special design of the facility and the length of the belts $\left(\mathrm{L}_{\text {belt }}=5,000 \mathrm{~mm}\right)$ enables a considerable reduction of measurement time. For the present investigation, two clusters of rods with constant diameter of $2 \mathrm{~mm}$ are attached to the belts. The two clusters with spacings $S_{R}=160 \mathrm{~mm}$ and $S_{R}=80$ are separated by a section which does not have any rods, simulating steady state case $\left(S_{R}=\infty\right)$. Thus, it is possible to measure sequentially the effect of three different spacings at a single boundary layer point. To clearly define the influence domain of each individual cluster with the other one, the clusters are separated by a certain distance. Using the triggering system mentioned above and a continuous data acquisition, the buffer zones between the data clusters are clearly visible. The data analysis program removes the buffer zones and extracts the data pertaining to each cluster. Comprehensive preliminary measurements were carried out to ensure that the data were exactly identical with the data obtained with an arrangement of rods filling the entire belt at constant spacing.

The cascade test section, located downstream of the wake generator, includes 5 blades with a height of 200.0 $\mathrm{mm}$ and a chord of $203.44 \mathrm{~mm}$, Fig.2. The airfoil used 
is the Pratt \& Whitney "Pak B" airfoil, whose cascade geometry is given in Table 1 . The cascade test section exhibits the essential flow features such as laminar boundary layer separation that is inherent to typical LPT- blades. The blade geometry was made available to NASA researchers and academia to study the specific problems of LPT-flow separation, its passive and active control and its prevention. As shown in [9], a minimum blade number of 5 is necessary and sufficient to secure a spatial periodicity for the cascade flow. The periodicity was verified by comparing the pressure distributions of blade number 2 (SPB-1) and 4 (SPB-2) shown in Fig. 2. These blades were specially manufactured for measurement of pressure and showed identical pressure distributions. A computer controlled traversing system is used to measure the inlet velocities and turbulence intensities, as well as the boundary layers on the suction and pressure surfaces. The traversing system is vertically mounted on the plexiglass side wall. It consists of a slider and a lead screw that is connected to a DC-stepper motor with an encoder and decoder. The optical encoder provides a continuous feedback to the stepper motor for accurate positioning of the probes. The system is capable of traversing in small steps up to $2.5 \mu \mathrm{m}$, which is specifically required for boundary layer investigations where the measurement of the laminar sublayer is of particular interest.

\section{INSTRUMENTATION, DATA ACQUISITION, AND DATA REDUCTION}

The data acquisition system is controlled by a personal computer that includes a 16 channel, 12-bit analog-digital (A/D) board (NI, PCI-MIO-16E-1). Time dependent velocity signals are obtained by using a commercial 3-channel (TSI, IFA-100), constant temperature hot-wire anemometer system that has a signal conditioner with a variable low pass filter and adjustable gain. A Prandtl probe, placed upstream of the diffuser, monitors the reference velocity at a fixed location. The pneumatic probes are connected to high precision differential pressure transducers (MKS $220 \mathrm{CD}$, range: 0 to $10 \mathrm{mmHg}$ ) for digital readout. Several calibrated thermocouple are placed downstream of the test section to constantly monitor the flow temperature. The wake generator speed and the passing frequency signals of the rods are transmitted by a fiberoptic trigger sensor. The passage signals of the rods are detected by the sensor using a silver-coated reflective paint on one of the belts. This sensor gives an accurate readout of the speed of the wake generator and the passing frequency of the rods. The signals of the pressure transducers, thermocouples, and trigger sensors are transmitted to the A/D board and are sampled by the computer. The second and fourth blade are each instrumented with 48 static pressure taps. The taps are connected to a scanivalve, which sequentially transferred the pressure signals to one of the transducers that was connected to the A/D board. Using Labview software, the data acquisition system including the computer and the A/D board was upgraded. Two adjacent blades are used for boundary layer measurement.

Steady and unsteady data are taken by angle calibrated, custom designed miniature single hot wire probes. At each boundary layer position samples were taken at a rate of $20 \mathrm{kHz}$ for each of 100 revolutions of the wake generator and low pass filtered at $10 \mathrm{kHz}$. The data were ensemble-averaged with respect to the rotational period of the wake generator. Before final data were taken, the number of samples per revolution and the total number of revolutions were varied to determine the optimum settings for convergence of the ensembleaverage.

For the steady state case, the instantaneous velocity components are calculated from the temperature compensated instantaneous voltages by using the calibration coefficients. The instantaneous velocity can be represented in the following form.

$$
V=\bar{V}+v
$$

Where $\bar{V}$ is the mean (time-averaged) velocity and $\mathrm{v}$ is the turbulent fluctuation component. The mean velocity, also known as the time-average, is given by:

$$
\bar{V}=\frac{1}{M} \sum_{j=1}^{M} V_{j}
$$

where $M$ is the total number of samples at one boundary layer location. The root mean square value of the turbulent velocity fluctuation is obtained from the instantaneous and mean velocities by:

$$
v=\sqrt{\frac{1}{M} \sum_{j=1}^{M}\left(V_{j}-\bar{V}\right)^{2}}
$$

and the local turbulence intensity is defined as:

$$
T u_{\text {loc }}=\frac{v}{\bar{V}} \times 100=\frac{1}{\bar{V}} \sqrt{\frac{1}{M} \sum_{j=1}^{M}\left(V_{j}-\bar{V}\right)^{2}} \times 100
$$

The ensemble-averaged velocity, fluctuation velocity, and the turbulence intensity were calculated from the instantaneous velocity samples by: 


$$
\begin{gathered}
V_{i}\left(t_{i}\right) \equiv\left\langle V_{i}\left(t_{i}\right)>=\frac{1}{N} \sum_{j=1}^{N} V_{i j}\left(t_{i}\right)\right. \\
\left.v_{i}\left(t_{i}\right) \equiv<v_{i}\left(t_{i}\right)\right\rangle=\sqrt{\frac{1}{N} \sum_{j=1}^{N}\left[V_{i j}\left(t_{i}\right)-\left\langle V_{i}\left(t_{i}\right)>\right]^{2}\right.}(6) \\
<T u_{i}\left(t_{i}\right)>\equiv\left\langle T u_{i}\left(t_{i}\right)\right\rangle=\frac{\left\langle v_{i}\left(t_{i}\right)\right\rangle}{\langle V(t)\rangle_{\text {ref }}} \times 100
\end{gathered}
$$

where $\mathrm{N}=100$ is the total number of wake generator periods and $\mathrm{M}$ the number of samples taken per period. $\langle\mathrm{V}(\mathrm{t})\rangle_{\text {ref }}$ is the reference ensemble averaged velocity for the particular boundary layer traverse. The ensemble-averaged boundary layer parameters such as displacement thickness $\left\langle\delta_{1}\right\rangle$, momentum thickness $\left\langle\delta_{2}\right\rangle$, and shape factor $\left\langle\mathrm{H}_{12}\right\rangle$ are calculated as follows:

$$
\begin{gathered}
\delta_{1} \equiv<\delta_{1}>=\int_{0}^{<\delta>}\left(1-\frac{<V>}{<V\rangle_{e}}\right) d y \\
\delta_{2} \equiv<\delta_{2}>=\int_{0}^{<\delta>} \frac{<V>}{<V\rangle_{e}}\left(1-\frac{<V>}{<V\rangle_{e}}\right) d y \\
H_{12} \equiv<H_{12}>=\frac{<\delta_{1}>}{<\delta_{2}>}
\end{gathered}
$$

In the above equations the signs $<>$ refer to ensemble averaged quantities. For brevity we will drop $<>$ in the following discussions.

\section{EXPERIMENTAL RESULTS AND DISCUSSION}

Detailed surface pressure and boundary layer measurements were performed at three different Renumbers. For each Reynolds number three different reduced frequencies were applied. For generation of unsteady wakes, cylindrical rods with the diameter $\mathrm{d}_{\mathrm{R}}=$ $2 \mathrm{~mm}$ were chosen to fulfill the similarity criterion that requires the generation of a drag coefficient $C_{D}$ that is approximately equal to the $C_{D}$ of the turbine blade with the chord and spacing given in Table 1 (for details we refer to the studies in [21] and [22].

To accurately account for the unsteadiness caused by the frequency of the individual wakes and their spacings, the flow velocity, and the cascade parameters, we define a reduced frequency $\Omega$ that includes the cascade solidity $\sigma$, the flow coefficient $\varphi$, the blade spacing $S_{B}$, and the rod spacing $S_{R}$. Many researchers have used Strouhal number as the unsteady flow parameter, which only includes the speed of the wake generator and the inlet velocity. However, the currently defined reduced frequency $\Omega$ is an extension of Strouhal number in the sense that it incorporates the rod spacing $S_{R}$ and the blade spacing $S_{B}$ in addition to the inlet velocity and wake generator speed. For surface pressure measurement rods with uniform spacings as specified in Table 1 were attached over the entire belt length. For boundary layer measurement, however, clusters of rods were used, as described previously.

\section{Surface Pressure Distributions}

Detailed static surface pressure measurements were taken at $\operatorname{Re}=50,000,75,000,100,000$, and 125,000 using the two static pressure blades SPB-1 and SPB-2 shown in Fig. 2. The two blades measured identical static pressure distributions confirming the spatial periodicity. For each Reynolds number three different reduced frequencies, namely $\Omega=0.0,1.59$, and 3.18, are applied that correspond to the rod spacings $S_{R}=\infty, 160 \mathrm{~mm}$, and $80 \mathrm{~mm}$. The pressure distributions in Fig. 3, which pertain to SPB-1, show the results of one steady and two unsteady cases. The pressure signals inherently signify the time-averaged pressure because of the internal pneumatic damping effect of the connecting pipes to the transducer. The noticeable deviation in pressure distribution between the steady and unsteady cases, especially on the suction surface, is due to the drag forces caused by the moving rods. The drag forces are imposed on the main stream and cause momentum deficiency that lead to a reduction of the total and static pressure.

The time-averaged pressure coefficients along the pressure and suction surfaces are plotted in Fig. 3. Starting with $\mathrm{Re}=50,000$ and steady state with $\Omega=0$ shown in Fig 3a, the suction surface (upper portion), exhibits a strong negative pressure gradient. The flow accelerates at a relatively steep rate and reaches its maximum surface velocity that corresponds to the minimum $c_{p}=-4.0$ at $s / s_{0}=0.42$. Passing through the minimum pressure, the fluid particles within the boundary layer encounter a positive pressure gradient that causes a sharp deceleration until $s / s_{0}=0.55$ has been reached. This point signifies the beginning of the laminar boundary layer separation and the onset of a separation zone. As seen in the subsequent boundary layer discussion, the part of the separation zone characterized by a constant $\mathrm{c}_{\mathrm{p}}$ - plateau extends up to $s / s_{0}=0.746$, thus occupying more than $19 \%$ of the suction surface. 

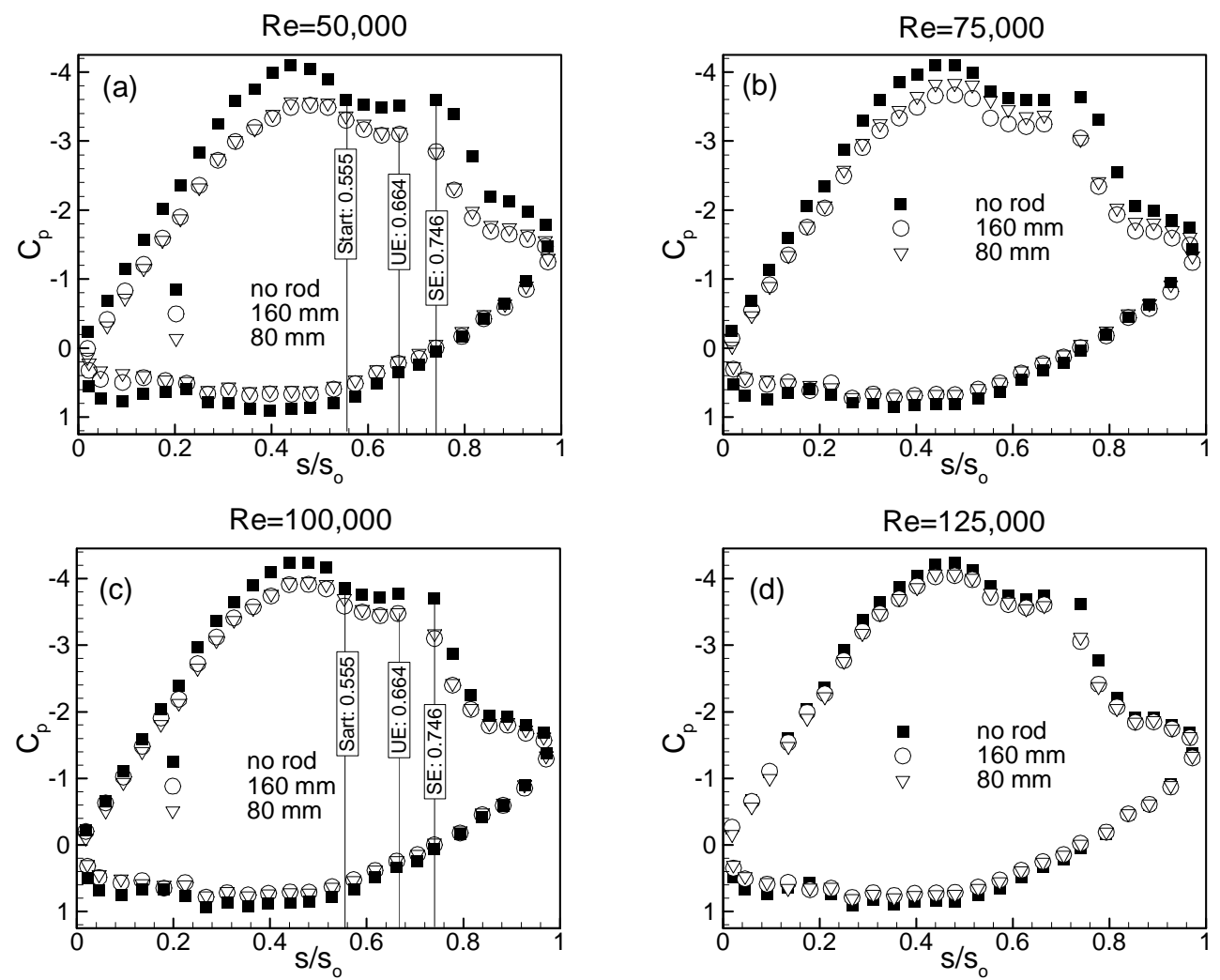

Fig. 3: Static pressure distribution at four different Re-numbers and reduced frequencies $\Omega=0$, 1,59, 3.18 (no rod, $160 \mathrm{~mm}, 80 \mathrm{~mm}$ ), Start= Separation start for steady and unsteady cases, $\mathrm{SE}=$ Separation end for steady case, $\mathrm{UE}=$ Separation end for unsteady cases.

Passing the plateau, the flow first experiences a second sharp deceleration indicative of a process of reattachment followed by a further deceleration at a moderate rate. On the pressure surface, the flow accelerates at a very slow rate, reaches a minimum pressure coefficient at $s / s_{0} \approx 0.42$ and continues to accelerate until the trailing edge has been reached. Unlike the suction surface, the pressure surface boundary layer does not encounter any adverse positive pressure gradient that triggers separation. However, close to the leading edge, a small depression in the curve extending from $s / s_{0} \approx 0.0 .8$ to 0.24 indicates the existence of a small size separation zone that might be attributed to a minor inlet flow incidence angle.

Considering the unsteady case with a reduced frequency of $\Omega=1.59$ that corresponds to a rod spacing of $S_{R}=160.0 \mathrm{~mm}$, Fig.3(a) exhibits two distinctive characteristics: (1) A noticeable deviation in pressure distribution between the steady and unsteady cases. As mentioned above, this deviation is attributed to the momentum deficiency that leads to a reduction of the total and static pressure. (2) For $R e<125,000$, the wakes have a substantial reducing impact on the streamwise extent of the separation plateau. As seen in Fig. 3(a), the trailing edge of the plateau has shifted from $s / s_{0}=0.746$ to $s / s_{0}=0.664$. This shift has reduced the streamwise extent of the separation plateau from $19 \%$ to less than $11 \%$ of the suction surface length which is, in this particular case, more than $42 \%$ reduction in streamwise extent of the separation plateau. Although the extent of the separation plateau is not necessarily identical with the extent of the separation zone, the relative reductions presented above adequately reflect the relative reduction of the size of the separation zone. Doubling the reduced frequency to $\Omega=3.18$ by utilizing a rod spacing of $S_{R}=80.0 \mathrm{~mm}$ causes a slight shift of the cp-distribution compared with $\Omega=1.59$-case. One should bear in mind that pneumatically measured surface pressure distribution represents a time integral of the pressure events only. Detailed information regarding the structure of the separation zone requires a detailed unsteady boundary layer or surface pressure measurement by fast response probes, as will be discussed in the subsequent sections. Increasing the 
Reynolds number to $R e=75,000$, has not brought major changes in steady state $c_{p}$-distribution. This is also true for the subsequent higher Reynolds number cases at steady state, Fig. 3(b,c,d). However, the combination of higher Re-number with unsteady wakes reveals that the noticeable deviation in pressure distribution between the steady and unsteady cases discussed above is diminishing with increasing the Renumber as shown in Figs. 3(b,c,d). Two counteracting factors are contributing to this deviation. The first factor is attributed to the momentum deficiency and the associated total pressure losses caused by moving wakes, as discussed above. The second factor pertains to the energizing effect of the impinging wakes on the boundary layer. Although the impinging wakes cause velocity and momentum deficits, their high turbulence intensity vortical cores provide an intensive exchange and transfer of mass, momentum, and energy to the blade surface, thus energizing the low energetic boundary layer. In conjunction with the surface pressure distribution, the kinetic energy of the normal velocity fluctuation component plays a crucial role. In case of a low Re-number flow, the strong damping effect of the wall shear stress has the tendency to reduce the normal contribution of turbulence kinetic energy, thereby diminishing its surface pressure augmenting effect. Increasing the Reynolds number results in a decrease of the damping effect of the wall shear stress, allowing the kinetic energy of the normal velocity fluctuation component to increase the surface pressure, thus offsetting the wake deficit effects on the pressure distribution. This fact is clearly shown in Fig. 3(a,b,c,d), where the pressure distributions of unsteady flow cases at $\Omega=1.59$ and $\Omega=3.18$ systematically approach the steady state cases at $R e=75,000,100,000$ and very visibly at $R e=125,000$. It is worth noting that the impact of the unsteady wakes on the extent of the separation zone is preserved regardless of the Reynolds number variation performed in this study.

\section{Time Averaged Velocity Distributions}

Following the surface pressure investigations that mainly addressed the onset and extent of the separation zone discussed previously, comprehensive boundary layer measurements were performed to identify the streamwise and normal extent as well as the deformation of the separation zone under unsteady wake flow. The steady state case serves as the reference configuration.

Boundary layer profiles were taken for one steady and two unsteady inlet flow conditions on the suction surface along 31 streamwise locations parallel to the cascade front. After completing the velocity measurements, the boundary layer coordinates were transformed into a blade orthogonal coordinate system. Velocities at blade normal positions were obtained by interpolating their transformed values. The results showed almost no difference between the interpolated and non-interpolated velocity data. Experimental investigations were performed for three different values of $\Omega=0.0,1.59$, and 3.18. These values cover the reduced frequency range encountered in LPT-design and off-design operation conditions.

The effect of wake frequency on time averaged velocity and turbulence fluctuation distributions is shown in Fig. 4 at four representative streamwise locations for
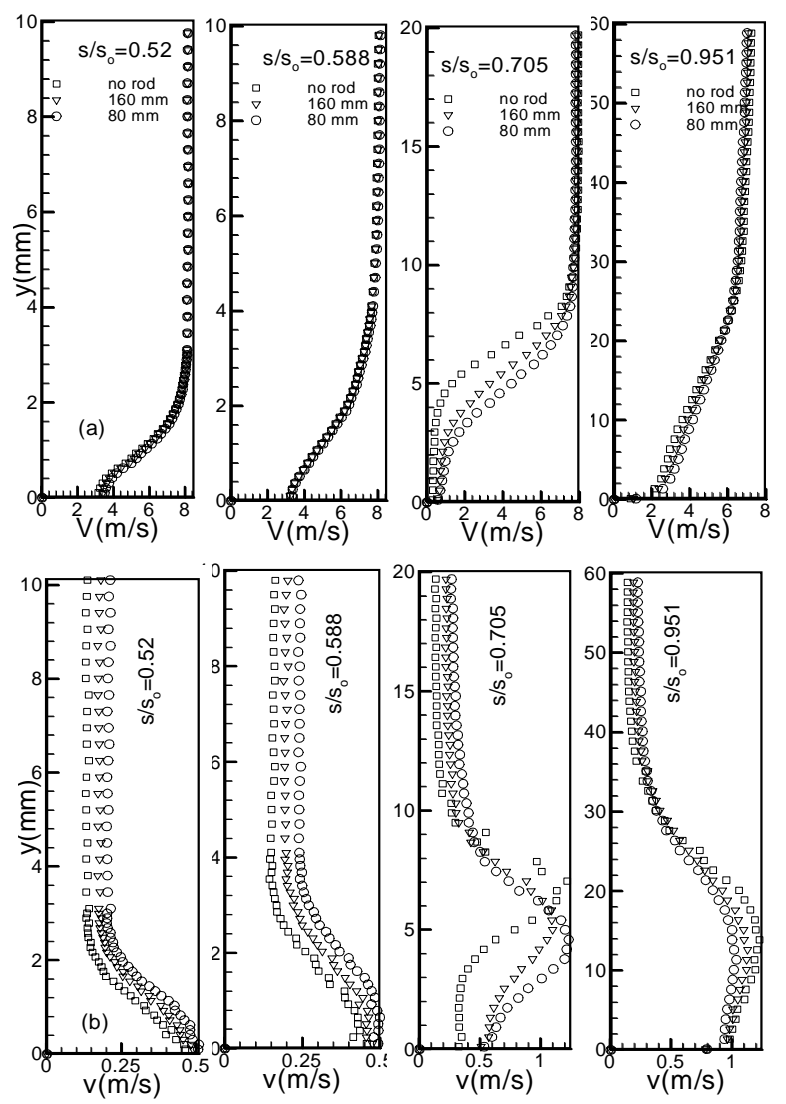

Fig. 4: Distribution of time averaged velocity (a) and fluctuation rms velocity (b) along the suction surface for steady case $\Omega=0\left(\mathrm{~S}_{\mathrm{R}}=\infty\right)$ and unsteady cases $\Omega=1.59$ $\left(S_{R}=160 \mathrm{~mm}\right)$ and $\Omega=3.18\left(S_{R}=80 \mathrm{~mm}\right)$ at $R e=110,000$. Note the changes in $y$-scale.

$\operatorname{Re}=110,000$. Upstream of the separation zone at $s / s_{0}=0.52$ and its proximity $s / s_{0}=0.588$, the velocity 
distributions inside the boundary layer are not affected by wakes. Inside the separation zone at $s / s_{0}=0.705$, a substantial influence of the wake frequency is observed. Higher wake frequency introduces fluctuation kinetic energy into the boundary layer which tends to reverse the separation tendency. Velocity distributions at $s / s_{0}=0.767,0.805,0.849$, and 0.898 (not presented) clearly show that the wake impingement shortens the streamwise extent of the separation zone compared to the steady case. Downstream of the separation zone, where the flow is fully reattached, $s / s_{0}=0.951$, the impact of wake on the boundary layer is reduced. This effect is clearly shown in the velocity distribution at $s / s_{0}=0.951$. In accord with the previous investigations by Schobeiri et al. [10] on a HP-turbine cascade, an increased wake frequency causes turbulence fluctuations to rise inside and outside the boundary layer as shown in Fig 4(b). However, once the boundary layer is re-attached and the velocity distribution assumes a turbulent profile, no major changes are observed in velocity as well as fluctuation distribution.

\section{Ensemble-Averaged Boundary Layer Velocity Distributions}

Figure 5 displays two representative temporal ensemble-averaged velocity distributions for (a) steady and (b) unsteady flow condition with their characteristic features. Both figures show the boundary layer development from the freestream to the blade surface at a streamwise position of $\mathrm{s} / \mathrm{s}_{\mathrm{o}}=0.0208$. Approaching the wall surface, both velocities experience a continuous deceleration. The velocity gradient in both cases causes generation and formation of vortices that transform the steady nature of case (a) into an unsteady one as clearly demonstrated in Fig. 5(a). The unsteady case displayed in Fig 5(b) is characterized by its deterministic temporal periodicity. Approaching the wall surface from $\mathrm{y}=10.1 \mathrm{~mm}$ to $3.45 \mathrm{~mm}$, the traveling periodic wake experiences a phase shift, while maintaining its deterministic nature. However, by penetrating into the boundary layer, the interaction between wake and boundary layer causes the deterministic nature to degenerate into a stochastic one. The results presented in Fig. 5 are in full agreement with those discussed in [7] and [12].

\section{Temporal Behavior of the Separation Zone Under Unsteady Wake Flow}

Velocity distributions on the suction surface with time as the parameter are plotted in Fig. 6. The
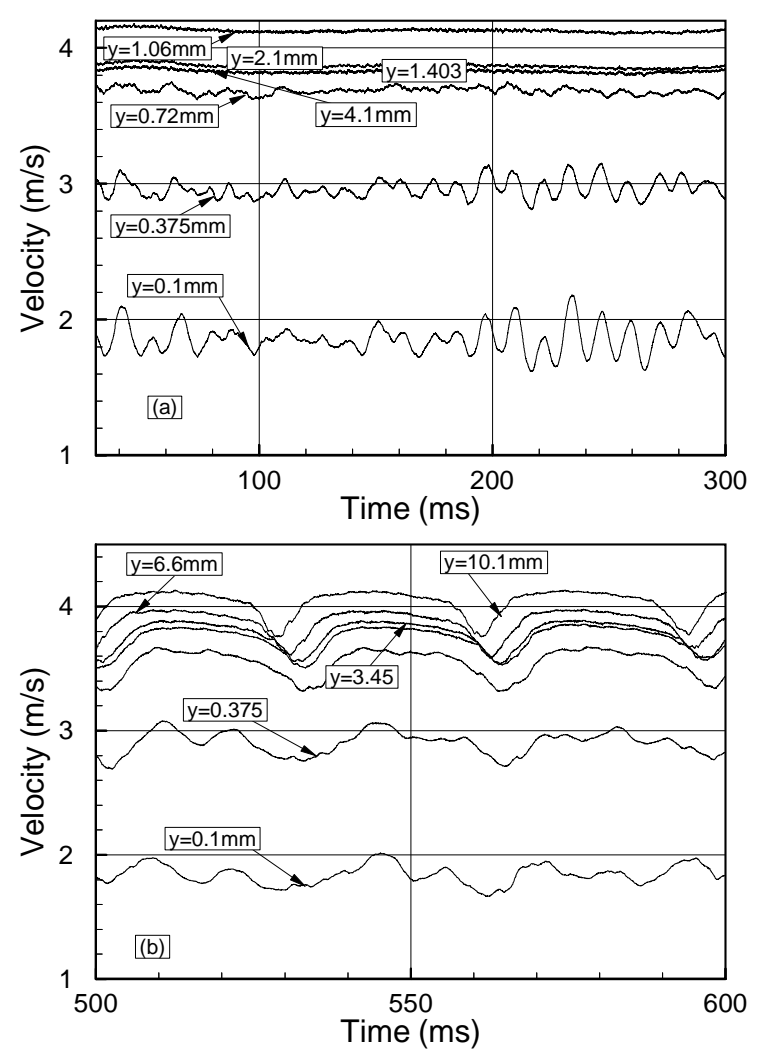

Fig. 5: Ensemble averaged velocity as a function of time for (a) steady flow case $\Omega=0\left(\mathrm{~S}_{\mathrm{R}}=\infty\right)$ and (b) unsteady case $\Omega=1.59\left(\mathrm{~S}_{\mathrm{R}}=160 \mathrm{~mm}\right)$ at $\mathrm{s} / \mathrm{so}=0.0208$ and $\operatorname{Re}=110,000$.

nondimensional time $(\mathrm{t} / \tau)$ values are chosen so that they represent the temporal states within one full period of wake passing. As Figs. 6(a) to 6(e) show, the velocity distributions inside and outside the boundary layer at fixed $\mathrm{s} / \mathrm{s}_{0}$-locations experience moderate to pronounced changes. Figure 6(a) represents the instantaneous velocity distribution upstream of the separation zone followed by Figs. 6(b,c,d,e) which represent the velocity distributions inside the separation zone. The last figure 6(f) exhibits the instantaneous velocity distribution downstream of the separation zone. In discussing the following results, we simultaneously refer to the wake distribution as well as the turbulence fluctuation results.

Figure 6(a) exhibits the velocity distribution on the suction surface at $\mathrm{s} / \mathrm{s}_{0}=0.402$. At this streamwise position, the laminar boundary layer is subjected to a strong negative pressure gradient. The boundary layer distributions at different $(t / \tau)$ experience changes in magnitude that reflect the corresponding changes of the impinging periodic wake velocity. It is worth noting, that despite the injection of turbulence kinetic energy by the 
impinging wakes, no local instantaneous boundary layer transition occurs. This is because of the strong negative pressure gradient that prevents the boundary layer from becoming instantaneously transitional. Instantaneous velocity distributions inside the separation zone are shown in Figs. 6(b,c,d,e,f).
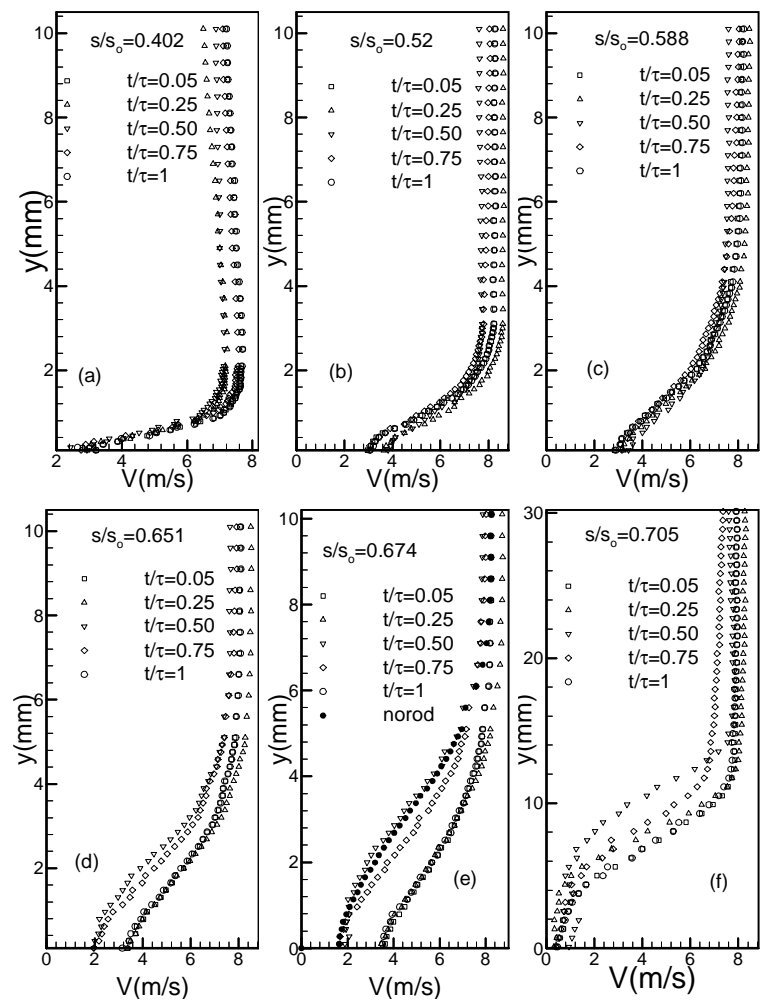

Fig. 6: Distribution of the ensemble averaged velocity development along the suction surface for different $\mathrm{s} / \mathrm{s}_{0}$ with time $t / \tau$ as parameter for $\Omega=1.59\left(S_{R}=160 \mathrm{~mm}\right)$ and $\operatorname{Re}=110,000$, note scale change in(f).

As a representative case, we discuss the results plotted in Fig. 6(e) at $\mathrm{s} / \mathrm{s}_{0}=0.674$. During the time interval from $t / \tau$ close to $0.5(1.5,2.5$, etc. $)$ to about $t / \tau=0.75$ $(1.75,2.75$ etc. $)$, the separation zone is exposed to the wake external flow being under the influence of relatively lower turbulence. This flow does not have the capability to suppress the separation zone. Thus the separation region is clearly shown by the velocity distributions at $t / \tau=0.5$ and $t / \tau=0.75$. As the wake passes over the blade at $\mathrm{s} / \mathrm{s}_{0}=0.674$ introducing high turbulence kinetic energy into the boundary layer, the boundary layer is energized causing the separation zone to partially reduce or disappear. This leads to an instantaneous re-attachment. This time interval corresponds to the case where the flow is completely under the influence of wake and correspondingly the reattached velocity distribution assumes a turbulent profile characterized by the curves at $\mathrm{t} / \tau=1.0, \mathrm{t} / \tau=$
0.05 , and $t / \tau=0.25$ shown in Fig 6(e). To emphasize this statement, the steady state velocity distribution at the same streamwise position is also plotted in Fig. 6(e) using full circles. It shows clearly the separated nature of the boundary layer which coincides with the instantaneous velocity profile at $t / \tau=0.5$. Intermediate times reflect the gradual change between the separation and re-attachment as the flow is undergoing the influence of the oncoming wake. Moving to the trailing edge of the separation zone, at $\mathrm{s} / \mathrm{s}_{0}=0.705$, Fig. 6(f), a partial reduction in boundary layer thickness as the result of wake impingement is visible, however, the separation zone does not seem to disappear.

\section{Temporal-Spatial Resolution of the Separation Zone}

To better understand the underlying physics of the LPT-flow separation, detailed unsteady flow measurements are performed to identify the onset and extent of the separation zone discussed previously. The separation zone can be thought of as a curve that connects the velocity inflection points along the suction surface. Starting with a reduced frequency of $\Omega=1.59$ $\left(\mathrm{S}_{\mathrm{R}}=160 \mathrm{~mm}\right)$ at $\mathrm{s} / \mathrm{s}_{0}=0.520$, Fig. 7 (a) exhibits the start of the separation zone with a normal extent of less than $1.0 \mathrm{~mm}$. The impingement of the periodic wake vortical core with the high turbulence intensity causes a local periodic contraction of the zone in normal direction. Convecting downstream, the normal extent increases, thus the contraction appears more pronounced, Fig 7 (b, $c, d)$. Substantial contraction occurs toward the trailing edge of the separation zone as shown in Fig. 7(e, f). Similar flow picture is observed when operating at a reduced frequency of $\Omega=3.18\left(\mathrm{~S}_{\mathrm{R}}=80 \mathrm{~mm}\right)$.

Studying the temporal distribution of the turbulence fluctuations along the streamwise extension of the separation zone, it is proposed that, in conjunction with the pressure gradient and periodic wakes, there is another crucial mechanism responsible for the normal and streamwise decrease of the separation zone. This mechanism constitutes a combination of the high turbulence fluctuation level and its gradient. It is the temporal gradient of the turbulence fluctuation, or more precisely, the fluctuation acceleration $\partial v_{r m s} / \partial t$ that provides higher momentum and energy transfer into the boundary layer energizing the separation zone and causing it to partially or entirely disappear. 


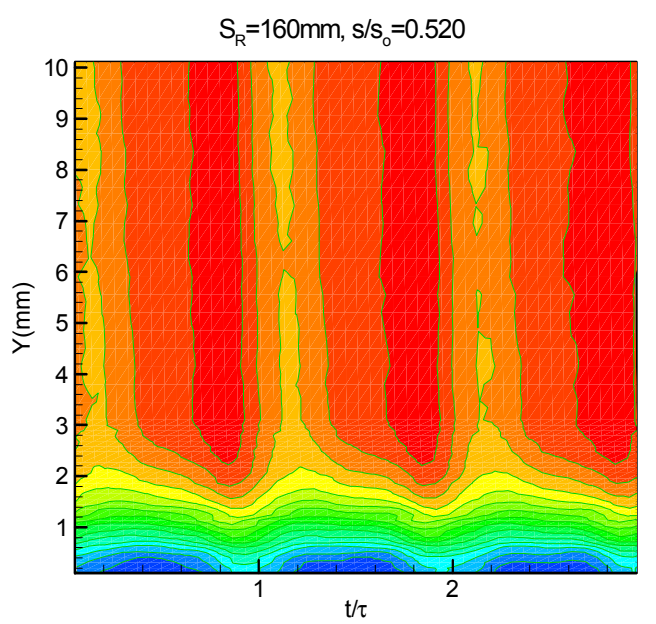

(a)

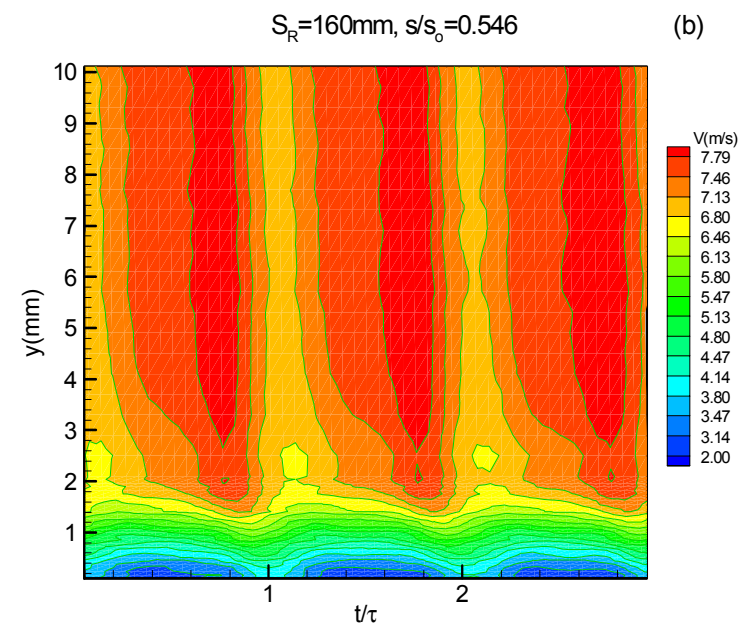

$\mathrm{S}_{\mathrm{R}}=160 \mathrm{~mm}, \mathrm{~s} / \mathrm{s}_{\mathrm{o}}=0.588$

(c)

$\mathrm{S}_{\mathrm{R}}=160 \mathrm{~mm}, \mathrm{~s} / \mathrm{s}_{\mathrm{o}}=0.617$

(d)
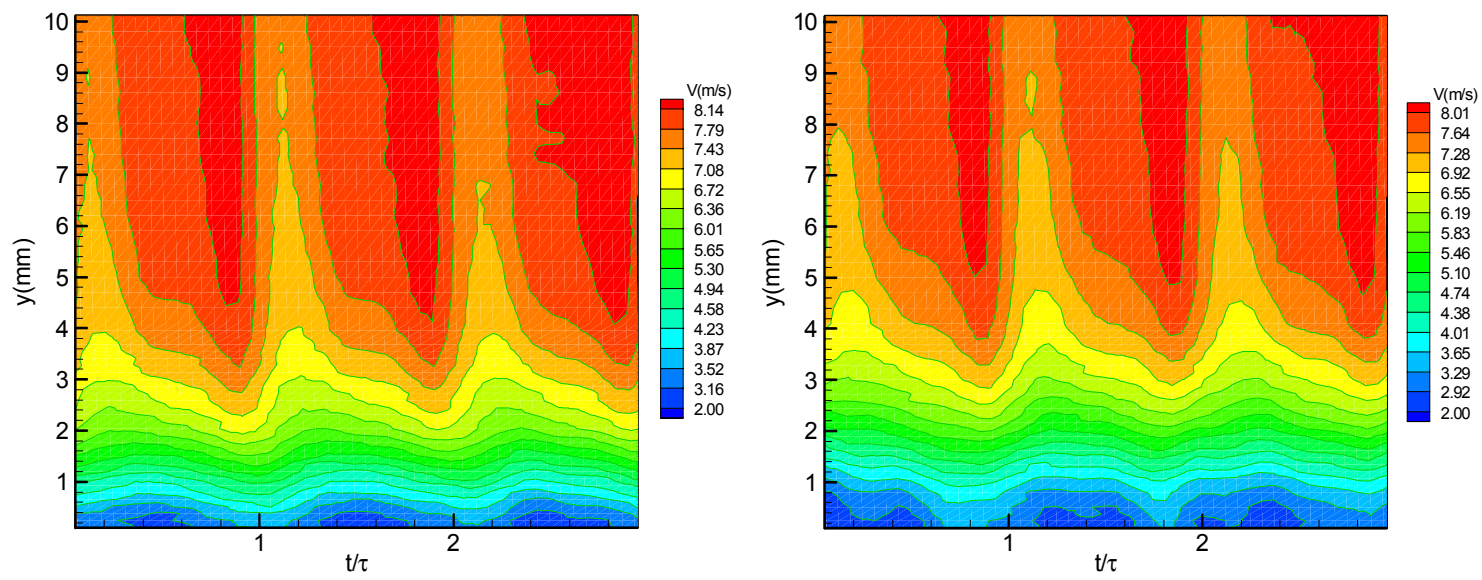

$\mathrm{S}_{\mathrm{R}}=160 \mathrm{~mm}, \mathrm{~s} / \mathrm{s}_{\mathrm{o}}=0.651$

(e)
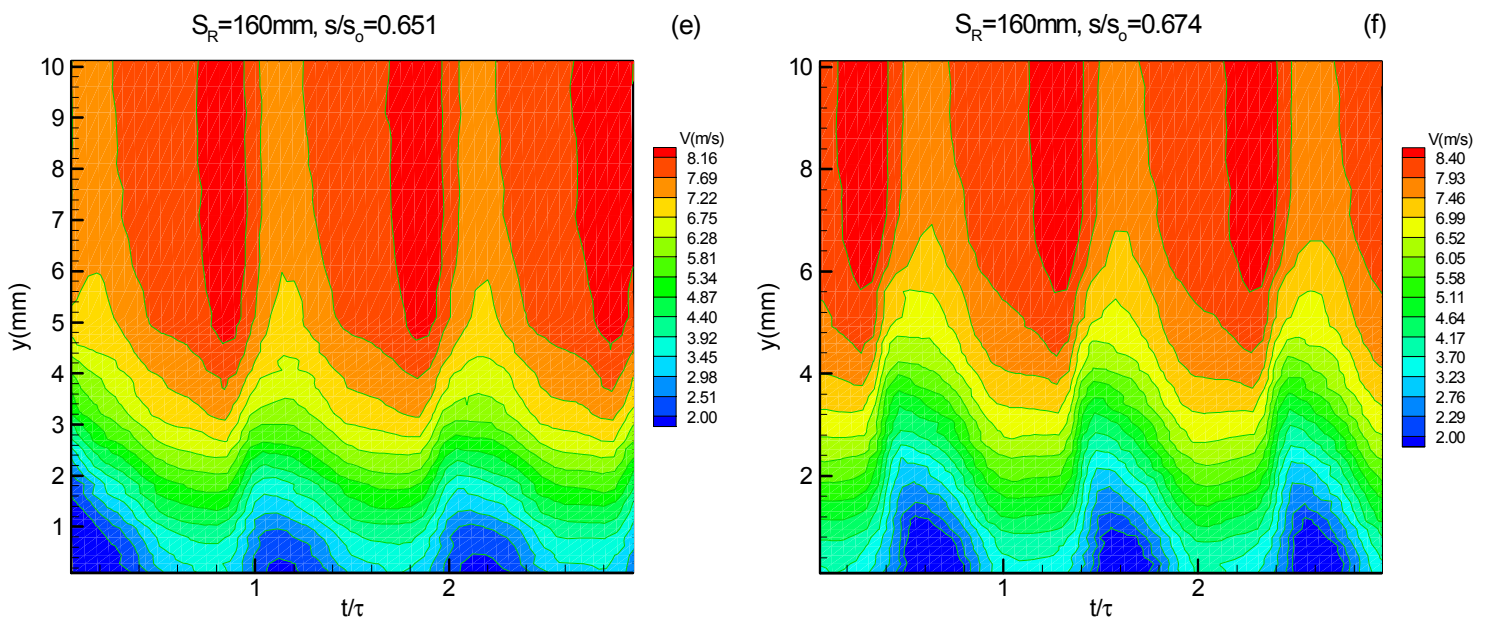

Fig. 7: Contour plot of the ensemble averaged velocity distribution showing the effect of periodic wakes on the separation zone at different streamwise positions and $\mathrm{Re}=110,000$. 
For better understanding this phenomenon, we present the wake and the fluctuation velocity in Fig. 8 for the streamwise position $s / s_{0}=0.651$ indicated in Fig. 7(e). For the sake of clarity, we scale up the fluctuation velocity with a factor of 4 and choose an arbitrary normal position of $y=2.85 \mathrm{~mm}$ to be sufficiently above the separation zone.

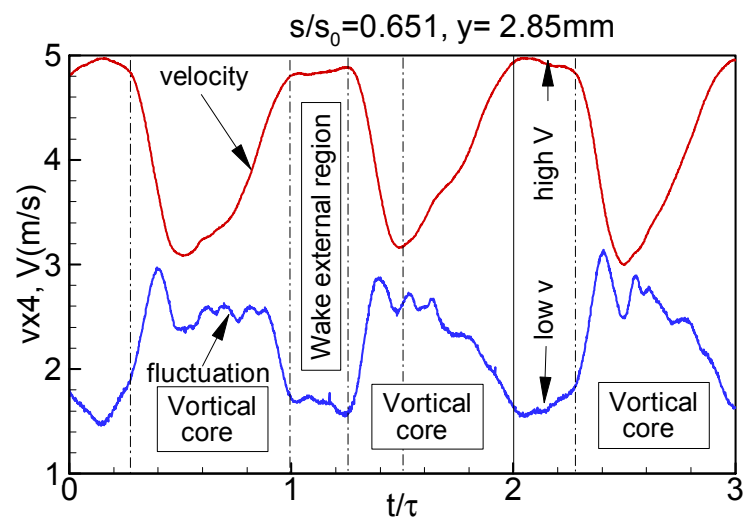

Fig. 8: Wake velocity and fluctuation rms distribution, $\mathrm{Re}=110,000$.

Figure 8 exhibits two distinct regions: (1) a wake vortical core, occupied by vortices that originate from the moving cylindrical rods and generate high turbulence fluctuations, and (2) a wake external region between the adjacent vortical cores with relatively low turbulence activities. The wake configuration is asymmetric as discussed in [21. Figure 7(e) is enlarged in Fig. 9 to reveal further details.

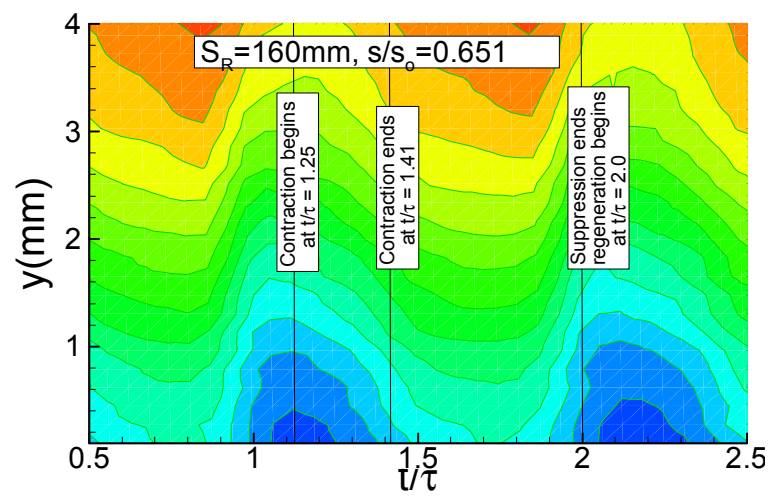

Fig. 9: Separation zone, definition of contraction begin, contraction end, suppression, and regeneration.

As Fig. 9 shows, the separation zone starts to contract at $t / \tau=1.25$ (2.25 etc.) This point coincides with the streamwise position of the velocity maximum, which exactly corresponds to the position of the fluctuation minimum, as shown in Figs. 8 and 10. At this point, the fluctuation within the vortical core starts to increase while the velocity continuously decreases. This process continues until the end contraction at $t / \tau=1.41$ has been reached. Thereafter, the separation zone is subjected to a process of intensive exchange of momentum and energy that causes the separation to diminish, as shown in Fig. 9. The process of separation contraction, suppression, and regeneration is summarized in Fig. 10. It shows more

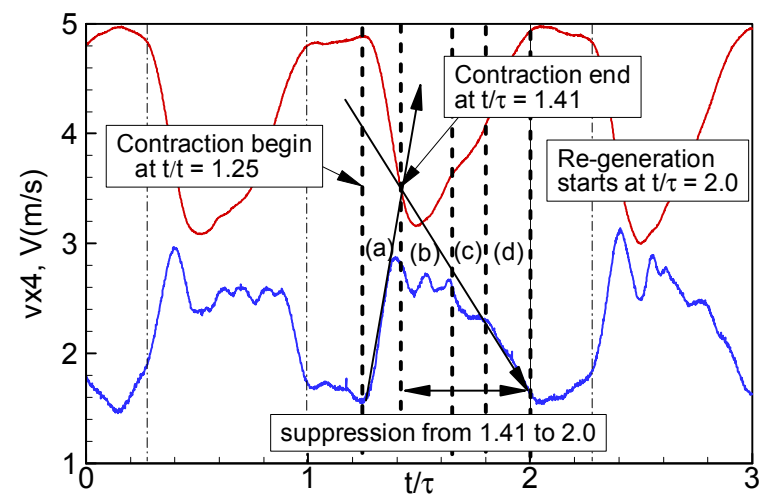

Fig. 10: Separation contraction, suppression, and regeneration, $\mathrm{Re}=110,000$.

details of separation contraction and suppression. In this context, it is necessary to subdivide the vortical core shown in Fig. 8 into four distinct regions, separated by thick dashed lines, as presented in Fig. 10. Region (a) is characterized by the initial positive gradient of the fluctuation $\partial \boldsymbol{v} / \partial \boldsymbol{t}>0$ marked with an upward arrow. Region (b) represents the substantial part of the vortical core with an intense turbulence activity. Region (c) serves as a transition region between region (b) and the relatively calm region (d) characterized by $\partial v / \partial t<0$.

For an initial fluctuation gradient $\partial v / \partial t>0$, the separation zone begins to contract at $t / \tau=1.25$. This initial gradient is crucial for initiating the contraction process. Once the maximum fluctuation velocity with the temporal gradient $\partial v / \partial t=0$ at $t / \tau \approx 1.41$ is reached (region a), the process of energizing the separation zone starts transferring momentum and energy into the separation zone, thereby preventing its regeneration (region b). Passing the transition region (c), the process of suppression continues until the end of the vortical region at $t / \tau \approx 2.0$ is reached. At this point the external wake region with its low turbulence content arrives causing a regeneration of the separation zone, thus reversing the entire suppression process.

While turbulence fluctuation expressed in terms of higher turbulence intensity is well known for influencing the flow separation, its gradient enhances the effect of 
delaying the onset and reducing the extent of the separation zone. The fluctuation gradient is an inherent feature of the incoming periodic wake flow and does not exist in a statistically steady flow that might have high turbulence intensity.

The results clearly indicate that for the particular blade under investigation, one has to deal with a large separation on the suction surface. These observations in comparison with the steady state reference case suggest that, once a separation zone is manifested, its size can be significantly reduced by periodic wake impingement, but it cannot be completely removed. The results presented here are valid for blades with a similar pressure distribution discussed earlier. Since the onset and extent of the separation zone is uniquely associated with the pressure gradient, blades can be designed with
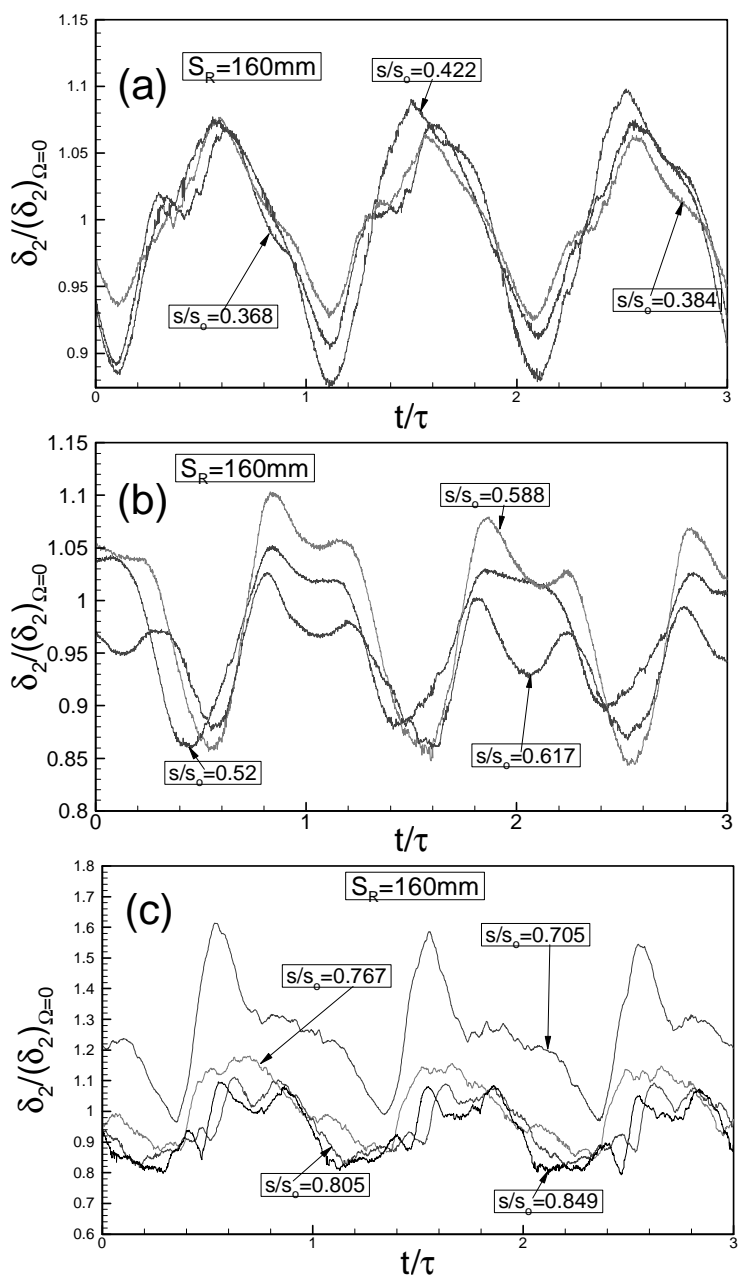

Fig. 11: Ensemble-averaged relative momentum thickness distribution along the suction surface for $\Omega=1.59\left(\mathrm{~S}_{\mathrm{R}}=160 \mathrm{~mm}\right)$ and $\mathrm{Re}=110,000$. less local adverse pressure gradient, whose separation onset can completely be suppressed by impinging wakes.

\section{Boundary Layer Ensemble Averaged Integral Quantities}

The integral parameters, such as momentum thickness and shape factor, are of particular interest to a turbine designer, since they provide an accurate first estimation of the quality of the designed blade. The ensemble-averaged distributions of the momentum deficiency thickness and shape factor for the suction surface are shown in Fig. $11(\mathrm{a}, \mathrm{b}, \mathrm{c}$,$) for \Omega=1.59$ at different $s / s_{0}$-locations . The momentum thickness values are non-dimensionalized with respect to the value corresponding to the steady case with $\Omega=0$. The period $\tau$ represents the wake-passing period that is specific to the individual wake generating cluster, which is characterized by the $\Omega$ - value under
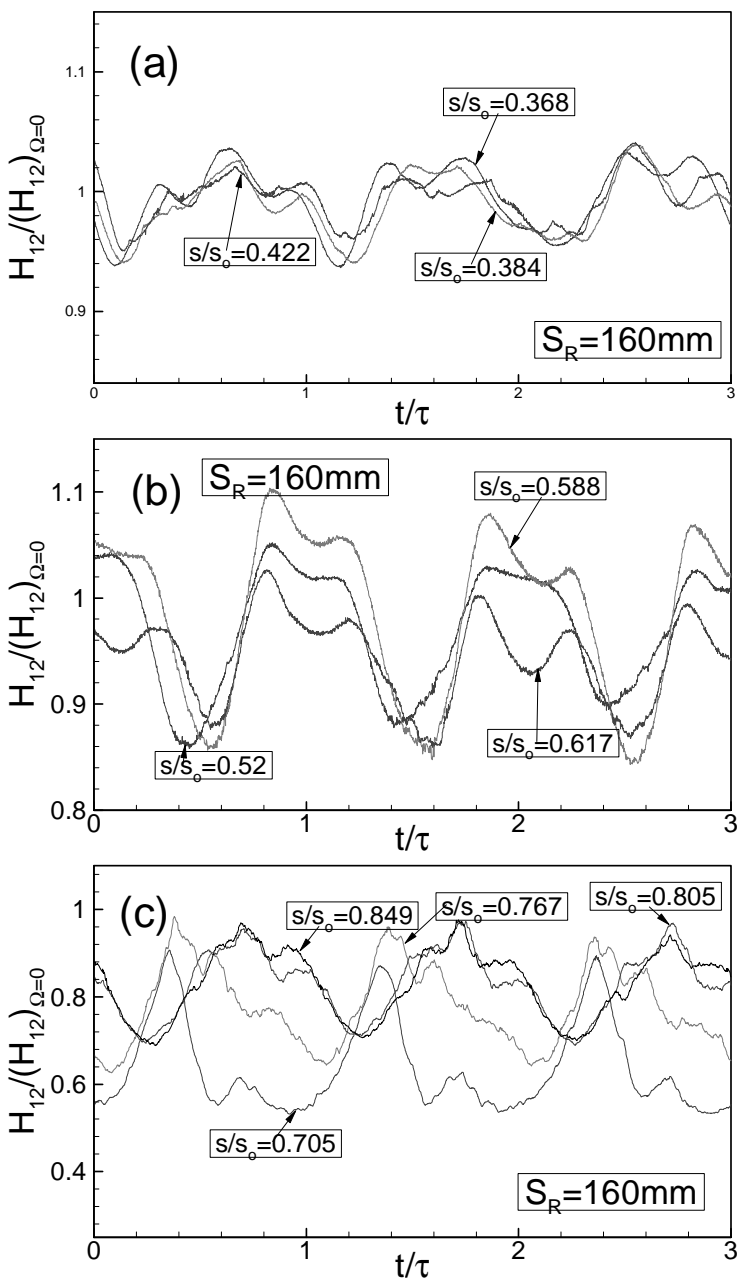

Fig. 12: Ensemble averaged relative form parameter distribution along the suction surface for $\Omega=1.59$ $\left(S_{R}=160 \mathrm{~mm}\right), \operatorname{Re}=110,000$. 
investigation. The periodic behavior of the ensembleaveraged momentum thickness over the entire suction surface as a result of the embedded periodic wake flow is clearly visible from Fig. 11. It represents the momentum thickness behavior at different $\mathrm{s} / \mathrm{s}_{0}-$ locations upstream, within and outside the separation zone. The relative momentum thickness distribution upstream of the separation zone in Fig. 11(a) integrally exhibits a slight increase, whereas inside the zone shown in Fig. 11(b), a substantial decrease is apparent. At the immediate vicinity of the separation zone trailing edge, $\mathrm{s} / \mathrm{s}_{0}=0.705$ close to re-attachment, Fig. $11(\mathrm{c})$, the momentum thickness experiences a noticeable increase, which by convecting downstream decreases again and approaches the integral values that are close to the steady state case.

The ensemble averaged relative shape factor $\mathrm{H}_{12}$ distributions on the suction surface at the same streamwise locations are plotted in Fig. 12(a,b,c). Upstream of the separation zone, Fig 12(a) they experience a similar periodic change with an average value that is close to the value of the steady case. Moving into the separation zone, Fig. 12(b,c), each streamwise location presents its own form parameter that is specific to the velocity distribution we discussed.

\section{CONCLUSIONS}

A detailed experimental study on the behavior of the separation zone on the suction surface of a highly loaded LPT-blade under periodic unsteady wake flow was presented. One steady and two different unsteady inlet wake flow conditions with the corresponding passing frequencies, wake velocity and turbulence intensities were investigated utilizing a new large-scale, subsonic research facility. The results of the unsteady boundary layer measurements were presented in ensemble-averaged, and contour plot forms. Surface pressure measurements were performed at $\mathrm{Re}=50,000$, 75,000, 100,000, and 125,000. At each Reynolds number, one steady and two periodic unsteady inlet flow measurements were performed. The surface pressure distribution showed no major changes with respect to the above Re-number changes. Noticeable changes occurred while operating at unsteady flow conditions. Detailed unsteady boundary layer measurement identified the onset and extent of the separation zone as well as its behavior under unsteady wake flow. Passing the wake flow with its highly turbulent vortical core over the separation region caused a periodic contraction and expansion of the separation zone. It was proposed that, in conjunction with the pressure gradient and periodic wakes, the temporal gradient of the turbulence fluctuation, or more precisely the fluctuation acceleration $\partial v_{r m s} / \partial t$ provides higher momentum and energy transfer into the boundary layer energizing the separation zone and causing it to partially or entirely disappear. We found that for $\partial v_{r m s} / \partial t>0$, the separation zone starts to contract whereas for $\partial v_{r m s} / \partial t<0$ it gradually assumes the shape before the contraction. The existence of higher turbulence fluctuations expressed in terms of higher turbulence intensity is well known for influencing the flow separation; its gradient is of crucial importance in suppressing or preventing the onset and the extent of the separation zone. The fluctuation gradient is an inherent feature of the incoming periodic wake flow and does not exist in a statistically steady flow that might have high turbulence intensity.

\section{UNCERTAINTY ANALYSIS}

The Kline and McClintock [23] uncertainty analysis method was used to determine the uncertainty in the velocity after calibration and data reduction for the singlewire probe. The Kline and McClintock method determines the uncertainty for a 95\% confidence level. The uncertainty in velocity for the single-wire probe after data reduction is given in Table 2 . As shown, the uncertainty in velocity increases as the flow velocity decreases. This is due to the pneumatic pressure transducer having a large uncertainty during calibration.

Table 2: Uncertainty in velocity measurement for hot-wire probe.

\begin{tabular}{||c|c|c|c||}
\hline$\overline{\mathrm{U}}(\mathrm{m} / \mathrm{s})$ & 3 & 5 & 12 \\
\hline$\omega \overline{\mathrm{U}} / \overline{\mathrm{U}}(\%)_{\mathrm{red}}$ & 5.78 & 2.41 & 1.40 \\
\hline
\end{tabular}

\section{REFERENCES}

[1] Pfeil, H., Herbst R., 1979, "Transition Procedure of Instationary Boundary Layers," ASME Paper, 79-GT-128.

[2] Pfeil, H., Herbst, R., Schröder, T., 1983, "Investigation of the Laminar Turbulent Transition of Boundary Layers Disturbed by Wakes," ASME Transactions, Journal of Engineering for Power, Vol. 105, pp. 130-137.

[3] Orth, U., 1993, Unsteady Boundary Layer Transition in Flow Periodically Disturbed by Wakes," ASME, Transactions Journal of Turbomachinery, Vol. 115, pp. 707-713. 
[4] Schobeiri, M. T., Radke, R. E., 1994, "Effects of Periodic Unsteady Wake Flow and Pressure Gradient on Boundary Layer Transition along the Concave Surface of a Curved Plate," ASME Paper 94-GT-327, presented at the International Gas Turbine and Aero-Engine Congress and Exposition, Hague, Niederlands, June 13-16, 1994.

[5] Schobeiri, M.T., Read, K. Lewalle, J.2002, "Effect of Unsteady Wake Passing Frequency on Boundary Layer Transition, Experimental Investigation and Wavelet Analysis," of Fluids Engineering, in press.

[6] Wright, L., Schobeiri, M. T., 1999, "The Effect of Periodic Unsteady Flow on Boundary Layer and Heat Transfer on a Curved Surface," ASME Transactions, Journal of Heat Transfer, November 1998, Vol. 120, pp. 22-33.

[7] Chakka, P., Schobeiri, M.T., 1999, "Modeling of Unsteady Boundary Layer Transition on a Curved Plate under Periodic Unsteady Flow Condition: Aerodynamic and Heat Transfer Investigations," ASME Transactions, Journal of Turbomachinery, January 1999, Vol. 121, pp. 8897.

[8] Liu, X., Rodi, W., 1991, "Experiments on Transitional Boundary Layers with Wake-Induced Unsteadiness," Journal of Fluid Mechanics, Vol. 231 pp. 229-256.

[9] Schobeiri, M. T., Pappu, K., Wright, L., 1995, "Experimental Study of the Unsteady Boundary Layer Behavior on a Turbine Cascade," ASME 95-GT-435, presented at the International Gas Turbine and Aero-Engine Congress and Exposition, Houston, Texas, June 5-8, 1995.

[10] Schobeiri, M. T., John, J., Pappu, K., 1997, "Experimental Study on the effect of Unsteadiness on Boundary layer Development on a Linear Turbine Cascade," Journal of Experiments in Fluids, 23 (1997), pp. 303-316.

[11] Schobeiri, M. T., Wright, L., Chakka, P., 1998 "Periodic Unsteady Flow Aerodynamics and Heat Transfer Studies on a Curved Surface, Combined Part I and II," in press , International Journal of Rotating Machinery.

[12] Schobeiri, M. T., Chakka, P., 2002, "Prediction of Turbine Blade Heat Transfer and Aerodynamics Using Unsteady Boundary Layer Transition Model," International Journal of Heat and Mass Transfer, 45 (2002) pp. 815-829
[13] Brunner, S, Fottner, L, Schiffer, 2000, “Comparison of two highly loaded turbine cascade under the influence of wake-induced transition," ASME 2000GT-268, presented at the International Gas Turbine and Aero-Engine Congress and Exposition, Munich, Germany, May 8-11, 2000.

[14] Cardamone, P, Stadtmüller, Fottner, L, Schiffer, 2000, "Numerical Investigation of the WakeBoundary Layer Interaction on a Highly Loaded LPTurbine Cascade Blade," ASME 2002-GT-30367, presented at the International Gas Turbine and Aero-Engine Congress and Exposition, Amsterdam, Niederlands, June 3-6, 2002.

[15] Schulte, V., Hodson, H. P., 1996, “Unsteady WakeInduced Boundary Layer Transition in High Lift LP Turbines," ASME Paper 96-GT-486.

[16] Kaszeta, R., W., Simon T. W, Ashpis, D.E., 2001,"Experimental Investigation of Transition to Turbulence as Affected by Passing Wakes ," ASME Paper 2001-GT-0195.

[17] Lou, W., Hourmouziadis, J., 2000,"Separation bubbles under Steady and Periodic Unsteady Main Flow Conditions,"ASME Paper 200-GT-270.

[18] Schröder, Th., 1989, "Measurements with hot-film probes and surface mounted hot film gages in a multi-stage low-pressure turbine," European Propulsion Forum, Bath, UK.

[19] Hauieisen V., Schröder, Th., Hennecke D., 1997, "Advanced Non-Intrusive for propulsion engines," AGARD-CP-598.

[20] Halstead, D.E., Wisler, D, C., Okiishi, T.H, Walker, G.J., Hodson, H.P., and Shin, H.-W, 1997, "Boundary layer development in axial compressors and turbines: Part 3 of 4," ASME Transactions, Journal of Turbomachinery, 119, pp. 225-237

[21] Schobeiri, M. T., John, J., Pappu, K., 1996, "Development of Two-Dimensional Wakes Within Curved Channels, Theoretical Framework and Experimental Investigation,”, ASME Transactions, Journal of Turbomachinery, July, 1996, Vol. 118, pp. 506-518.

[22] Eifler, J., 1975, "Zur Frage der freien turbulenten Strömungen, insbesondere hinter ruhenden und bewegten Zylindern," Dissertation D-17, Technische Hochschule Darmstadt, Germany.

[23] Kline, S. J., and McKlintock, F. A., "Describing Uncertainties in Single-Sample Experiments," Mechanical Engineering, Vol. 75, Jan. 1953, pp. 38. 
Public reporting burden for this collection of information is estimated to average 1 hour per response, including the time for reviewing instructions, searching existing data sources, gathering and maintaining the data needed, and completing and reviewing the collection of information. Send comments regarding this burden estimate or any other aspect of this collection of information, including suggestions for reducing this burden, to Washington Headquarters Services, Directorate for Information Operations and Reports, 1215 Jefferson Davis Highway, Suite 1204, Arlington, VA 22202-4302, and to the Office of Management and Budget, Paperwork Reduction Project (0704-0188), Washington, DC 20503.

\section{\begin{tabular}{l|l|l} 
1. AGENCY USE ONLY (Leave blank) & 2. REPORT DATE & 3. REPORT TYPE AND DATES COVERED
\end{tabular}}

4. TITLE AND SUBTITLE

June 2003

Technical Memorandum

On the Physics of Flow Separation Along a Low Pressure Turbine Blade Under

Unsteady Flow Conditions

5. FUNDING NUMBERS

6. AUTHOR(S)

WBS-22-708-28-07

Meinhard T. Schobeiri, Burak Öztürk, and David E. Ashpis

7. PERFORMING ORGANIZATION NAME(S) AND ADDRESS(ES)

National Aeronautics and Space Administration

John H. Glenn Research Center at Lewis Field

Cleveland, Ohio 44135-3191

8. PERFORMING ORGANIZATION

REPORT NUMBER

E-13852

\section{SPONSORING/MONITORING AGENCY NAME(S) AND ADDRESS(ES)}

National Aeronautics and Space Administration

Washington, DC 20546-0001

10. SPONSORING/MONITORING

AGENCY REPORT NUMBER

NASA TM-2003-212290

GT-2003-38917

\section{SUPPLEMENTARY NOTES}

Prepared for the Turbo Expo 2003 cosponsored by the American Society of Mechanical Engineers and the International Gas Turbine Institute, Atlanta, Georgia, June 16-19, 2003. Meinhard T. Schobeiri and Burak Öztürk, Texas A\&M University, Turbomachinery Performance and Flow Research Laboratory, College Station, Texas 77843; David E. Ashpis, NASA Glenn Research Center. Responsible person, David E. Ashpis, organization code 5820, 216-433-8317.

12a. DISTRIBUTION/AVAILABILITY STATEMENT

12b. DISTRIBUTION CODE

Unclassified - Unlimited

Subject Categories: 02, 34, and 07

Distribution: Nonstandard

Available electronically at http://gltrs.grc.nasa.gov

This publication is available from the NASA Center for AeroSpace Information, 301-621-0390.

\section{ABSTRACT (Maximum 200 words)}

The present study, which is the first of a series of investigations dealing with specific issues of low pressure turbine (LPT) boundary layer aerodynamics, is aimed at providing detailed unsteady boundary flow information to understand the underlying physics of the inception, onset, and extent of the separation zone. A detailed experimental study on the behavior of the separation zone on the suction surface of a highly loaded LPT-blade under periodic unsteady wake flow is presented. Experimental investigations were performed at Texas A\&M Turbomachinery Performance and Flow Research Laboratory using a large-scale unsteady turbine cascade research facility with an integrated wake generator and test section unit. To account for a high flow deflection of LPT-cascades at design and off-design operating points, the entire wake generator and test section unit including the traversing system is designed to allow a precise angle adjustment of the cascade relative to the incoming flow. This is done by a hydraulic platform, which simultaneously lifts and rotates the wake generator and test section unit. The unit is then attached to the tunnel exit nozzle with an angular accuracy of better than $0.05^{\circ}$, which is measured electronically. Utilizing a Reynolds number of 110,000 based on the blade suction surface length and the exit velocity one steady and two different unsteady inlet flowconditions with the corresponding passing frequencies, wake velocities and turbulence intensities are investigated using hot-wire anemometry. In addition to the unsteady boundary layer measurements, blade surface pressure measurements were performed at $\mathrm{Re}=50,000,75,000,100,000$, and 125,000 at one steady and two periodic unsteady inlet flow conditions. Detailed unsteady boundary layer measurement identifies the onset and extent of the separation zone as well as its behavior under unsteady wake flow. The results presented in ensemble-averaged and contour plot forms contribute to understanding the physics of the separation phenomenon under periodic unsteady wake flow. Several physical mechanisms are discussed.

14. SUBJECT TERMS

Boundary layer; Separation; Turbomachinery; Transition; Turbines; Bypass transition; Wakes; Turbulent spots

17. SECURITY CLASSIFICATION OF REPORT

Unclassified
18. SECURITY CLASSIFICATION OF THIS PAGE

Unclassified
19. SECURITY CLASSIFICATION OF ABSTRACT

Unclassified
15. NUMBER OF PAGES

22

16. PRICE CODE

20. LIMITATION OF ABSTRACT

Standard Form 298 (Rev. 2-89)

Prescribed by ANSI Std. Z39-18 298-102 